\title{
Are newly qualified doctors prepared to provide supportive and end-of-life care? A survey of Foundation Year I doctors and consultants
}

\author{
${ }^{1} \mathrm{~J}$ Bowden, ${ }^{2} \mathrm{~K}$ Dempsey, ${ }^{3} \mathrm{~K}$ Boyd, ${ }^{4} \mathrm{M}$ Fallon, ${ }^{5} \mathrm{SA}$ Murray \\ ${ }^{1}$ Registrar in Palliative Medicine, Royal Infirmary of Edinburgh; ${ }^{2}$ Fourth Year Medical Student, University of Edinburgh Medical School; \\ ${ }^{3}$ Consultant in Palliative Medicine, Royal Infirmary of Edinburgh; ${ }^{4}$ St Columba's Hospice Chair of Palliative Medicine, The University of \\ Edinburgh and Edinburgh Cancer Research Centre; ${ }^{5}$ St Columba's Hospice Chair of Primary Palliative Care, Primary Palliative Care Research \\ Group, The University of Edinburgh, Scotland, UK
}

\section{ABSTRACT}

Objective: To establish whether Foundation Year I (FYI) doctors in Edinburgh are sufficiently prepared to deliver generalist palliative care, with a view to informing developments in undergraduate and postgraduate medical education.

Methods: Questionnaires were sent to FYI doctors and to supervising consultants. Semi-structured interviews were conducted with five FYI doctors.

Results: A total of $60 \mathrm{FYI}$ doctors and $3 \mathrm{I}$ consultants replied. The majority of FYI doctors did not feel well-prepared to deliver basic palliative care, especially when managing distress and social issues. Consultants agreed that FYI doctors were underprepared. Junior doctors reported high levels of distress themselves, with few seeking support from senior colleagues. Both sets of respondents made suggestions for curricular improvements.

Conclusions: Newly qualified doctors were not adequately prepared to deliver generalist palliative care and lacked first-hand experience of end-of-life issues. Current reviews of palliative care education should address the learning and supportive needs of our most junior doctors more effectively.

\author{
Correspondence to J Bowden \\ NHS Fife, Ward 16 \\ Queen Margaret Hospital \\ Whitefield Road, Dunfermline \\ Fife KYI2 OSU, UK
}

tel. $+44(0) 1383623623$

e-mail joannabowden@nhs.net

KEYWORDS Palliative care, undergraduate, education, teaching, learning

DECLARATION OF INTERESTS No conflict of interests declared.

\section{BACKGROUND}

Ensuring that all UK medical graduates are able to care for patients and families with palliative care needs has become a national priority. Tomorrow's Doctors (2009) stated that students must be able to contribute to the care of patients and their families at the end of life, including management of symptoms, deal with practical issues of law and certification, effectively communicate and work well in teams. Several other General Medical Council (GMC) learning outcomes also relate to palliative care, particularly ethics, safe prescribing and shared decision-making.' Medical schools in the UK, including the five schools in Scotland, are currently moving towards more outcome-focused curricula in line with GMC recommendations, and are reviewing their palliative care teaching to ensure it meets the requirements. There is increasing recognition of the importance of palliative care, though it is acknowledged that access to this care for those who need it varies greatly in different countries across Europe. ${ }^{2}$

In 2008, the Association for Palliative Medicine of Great Britain and Ireland (APM) published a recommended syllabus for medical undergraduates, following a Delphi study of palliative medicine specialists. ${ }^{3.4}$ This document provides a clear framework for palliative care educators, but has been described as 'not achievable in already overloaded undergraduate curricula'..$^{5}$ The Scottish Government action plan for palliative care and the Department of Health end-of-life care programme both highlight the need for better education and training of all health professionals. ${ }^{6.7}$ To inform the review of palliative care undergraduate medical curriculum and highlight potential areas for improvement, we surveyed FYI doctors and supervising consultants in South East Scotland. We aimed to find out if the Foundation Year I doctors felt able to care for patients and families with supportive and palliative care needs and to compare this with the views of consultants. We also investigated whether these junior doctors felt distressed when caring for patients at the end of life and asked them to identify their sources of support.

\section{METHODS}

A questionnaire for $\mathrm{FYI}$ doctors was developed as part of a fourth year 'student selected' project. A combination of ratings scales and open questions were used to allow comparison of key data and capture thoughts about 
individual experiences. Questionnaires were piloted with 14 senior medical students and minor revisions were made. Questions were grouped into three sections - undergraduate teaching experiences, FYI experiences, and recommendations for future undergraduate training.

Questionnaires were emailed to the $176 \mathrm{FYI}$ doctors working in the South East Scotland Deanery in November 2009. Reminders were sent twice. Paper copies were also distributed to FYI doctors in the two largest acute hospitals. Respondents were asked if they would consent to a short discussion and semi-structured interviews were conducted with a convenience sample of five FYI doctors who volunteered. They were asked to expand on themes included in the questionnaires. The aim was to generate narrative accounts that provided contextual descriptions of the doctors' experiences.

Data from the questionnaires were entered into a spreadsheet and basic comparative analysis was conducted. The interviews were tape-recorded and representative accounts were selected to highlight key findings from the questionnaires.

A consultant questionnaire was designed to explore similar issues. These questionnaires were distributed in early 2010 by hand to a convenience sample of 47 consultants from a range of medical and surgical specialties who were clinical or educational supervisors for FYI doctors. A reminder was sent after one month.

The project was approved as an educational needs assessment by the undergraduate special study module review group, and ethics committee approval was not considered necessary.

\section{RESULTS}

Sixty FYI doctors returned the questionnaire $(34 \%$ response rate), 40 of whom were female. The response rate from the consultants was $66 \%(n=31)$. The median number of FYI doctors supervised by each consultant during the four months since qualification was four.

\section{Undergraduate teaching and FYI preparedness for practice}

\section{FYI survey}

A total of 29/60 FYI doctors (48\%) felt that they had 'too little' palliative care education at medical school while 25/60 FYls were satisfied that the amount of palliative care education had been 'about right'; 40/60 FYI doctors (67\%) stated that at the point of graduation they were 'not very well prepared' to manage end-of-life issues in general, but the remaining 20 (33\%) felt 'well prepared.' One of the interviewees commented that undergraduate training only took them so far:
You can learn things up to a point as a medical student, but when you're actually in the position of having to do it on your own on the wards in the middle of the night by yourself you learn pretty quickly.

Respondents were asked to rate their preparedness in a number of key palliative care subjects, to try to establish which areas were most in need of development. Clinical communication and pain control were the areas that FYIs reported feeling most prepared for, while 'spiritual distress', 'social issues' and 'psychological distress' were those that they felt least prepared to manage (Figure I).

\section{Consultant survey}

Consultants rated their FYI doctors as generally less well prepared than the FYIs rated themselves to care for patients with a variety of palliative care needs (Figure 2 ).

'Pain control' was the area that the consultants saw their FYI doctors as most prepared for, with 'spiritual distress' and 'social issues' the poorest. Several consultants commented that they did not expect FYI doctors to be fully prepared to deliver palliative care.

\section{FYI doctor experience}

\section{FYI survey}

A total of 56/60 FYI doctors had been involved in some way in caring for dying patients since qualifying. Of these, $44(79 \%)$ had felt out of their depth, though the majority of these $(n=40,91 \%)$ stated that there was someone they could approach for advice about end-of-life care. The hospital palliative care teams and their senior colleagues were the most popular sources of advice.

I wasn't that shocked that I hadn't seen dying people, but the first time you see it is when you're a doctor and the families are asking questions and you've never met them before. That's the scenario you're faced with.

I would have liked to have been talked through how people die, like assessing when you think someone is dying and how long it takes different people to die. I didn't realise people could be dying for days.

A total of $39 / 60 \mathrm{FYI}$ respondents (65\%) had felt personally distressed when caring for patients with palliative care needs, with only around half of these $(n=18)$ believing that there was someone they could approach for support. For the most part, this support came from family and friends rather than their colleagues or senior consultants. None of the interviewees talked explicitly about feeling distressed.

\section{Consultant survey}

A total of $26 / 3$ I of the consultants believed that there were adequate learning opportunities available relevant to palliative care while working in their specialty, with a 


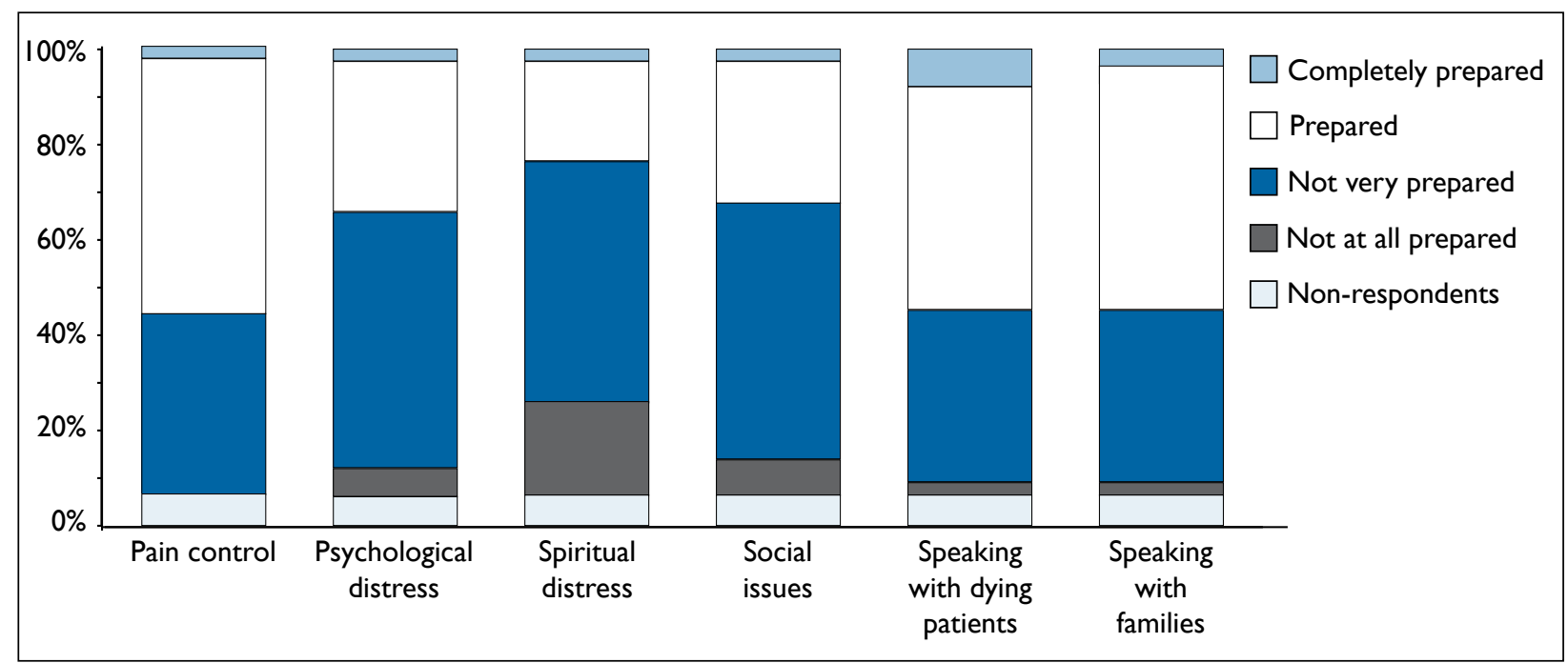

FIGURE I How prepared were you at graduation to manage the following?

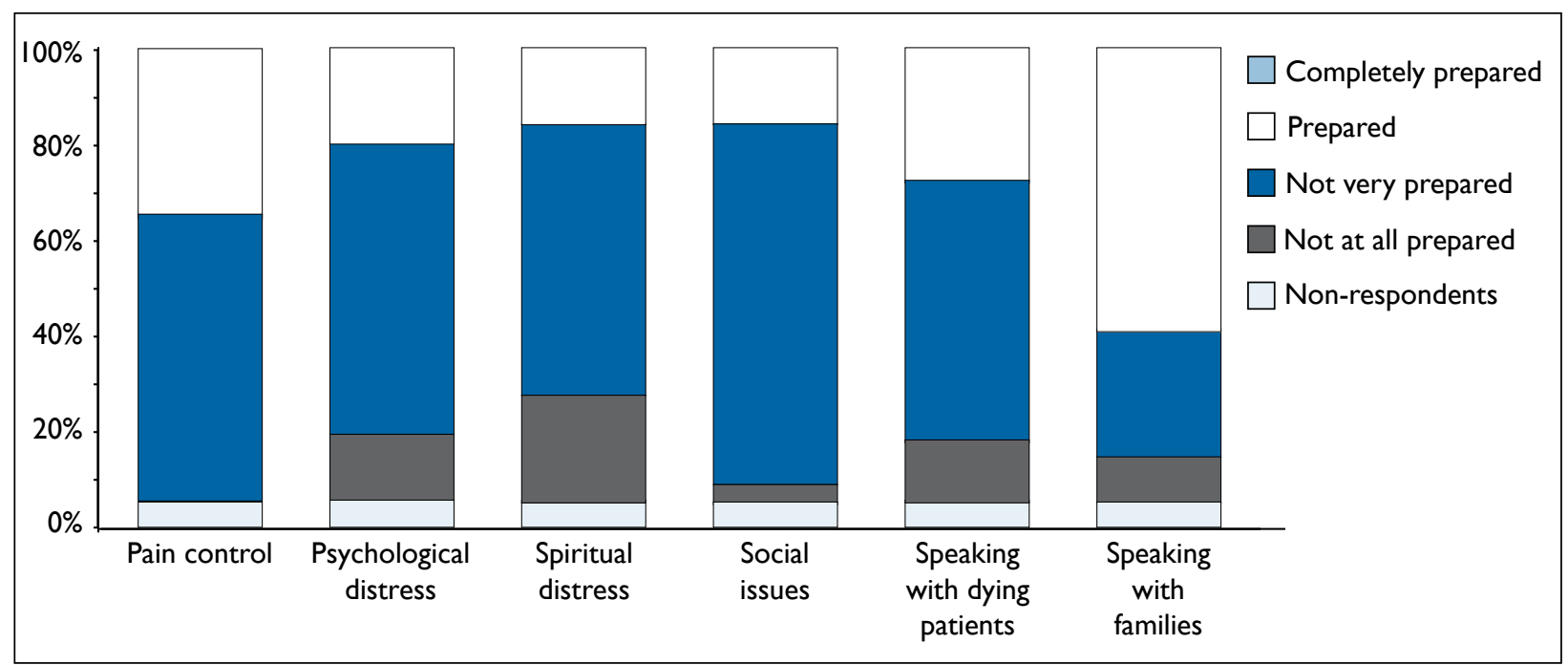

FIGURE 2 How prepared are the Foundation Year I doctors you supervise at managing the following?

similar number $(n=28)$ agreeing that the FYI doctors' abilities improved over their first year. Several commented that role-modelling by senior consultants played an important part in this.

A total of $26 / 3$ I of the consultants felt that FYI doctors would ask for their support appropriately, but few had actually provided assistance for FYls who were distressed at caring for patients at the end of life. Interestingly, 26/3 I respondents felt adequately prepared to provide support for FYIs.

\section{Suggestions for future undergraduate training}

\section{FYI survey}

A total of 28/60 FYI respondents made suggestions for a future curriculum; 18/28 suggested more practical sessions, 13/28 proposed more clinical exposure to patients nearing the end of life, and 6/28 suggested that more case-based teaching would be beneficial.
Just how to write up syringe drivers, what you can put in them, what you can prescribe for respiratory secretions, anti-emetics, that sort of thing. The practical side of things is probably most helpful.

Maybe if you were on a placement, you could get more involved and see what actually happens towards the end.

Case-based is good, so like, 'here's a kardex, what would you do?' make it very practical and teach us about stopping and rationalising meds and all that.

\section{Consultant survey}

Consultant respondents agreed with the FYIs that more exposure and hands-on experience of dealing with dying patients and those with difficult symptoms would be beneficial. Several proposed undergraduate attachments to hospital palliative care teams, while others suggested that they could deliver valuable ward-based teaching themselves. 


\section{DISCUSSION}

Most FYI doctors we surveyed felt that there had been insufficient undergraduate teaching in palliative care, although we cannot say that more education would necessarily equal better preparedness at the point of graduation. Many of the consultants thought that to expect 'preparedness' was unrealistic. A number of the FYI doctors reported that while they felt out of their depth and generally unprepared, this was acceptable given their junior status. However, we know that FYI doctors in all specialties will be caring for patients with palliative care needs in their first year of work..$^{5,9,10}$ They do not require specialist knowledge, but should be confident and competent in delivering holistic, generalist palliative care and be able to cope with the emotional demands of caring for dying patients and their families. Our survey demonstrated that newly qualified doctors in South East Scotland did not feel fully prepared to provide end-of-life care, especially with respect to managing psychological and spiritual distress and social issues. Studies in other settings have previously shown that junior doctors lack confidence in their ability to deliver palliative care. ${ }^{8,9}$ We do not know if our sample of FYI doctors would have rated their ability to deliver other types of medical care similarly to palliative care, as this was not included in the questionnaire.

Three-quarters of the FYI doctors surveyed had felt out of their depth while caring for patients with palliative care needs, and almost two-thirds had become distressed when caring for the dying. These findings are consistent with other studies and specifically with another recent Scottish survey of FYI doctors. ${ }^{10}$ Both surveys highlight that only around half of foundation doctors feel adequately supported in caring for a dying patient, and that most don't seek (or receive) much support from their senior colleagues in these circumstances. Our consultant survey supports this finding, but also raises the question of 'why not?' since the majority of consultants reported feeling adequately prepared to deliver such support.

Ten years ago, Field and Wee," and more recently Gibbins et al., ${ }^{5}$ found that palliative care education varied considerably among UK medical schools, with some having very little dedicated teaching time and others with longer clinical placements. Our survey highlighted that a number of FYI doctors had had little or no contact with dying patients or families during their clinical training. This is despite all students visiting inpatient hospice teams, and spending many months on hospital wards and in primary care placements. Gibbins et al. surveyed palliative care educators and found that the lack of hands-on experience was common. ${ }^{2}$ There was general acknowledgement that students were denied access to the most unwell patients, with one educator commenting that at their university students could go through the entire undergraduate medical course without ever seeing anybody with a lifethreatening illness. Comments from the FYI doctors we surveyed about not knowing how people died suggest this is an ongoing problem. In another survey, Arolker et al. interviewed palliative care professionals and patients and found that while staff acted as 'gatekeepers' by 'protecting' the most unwell patients from medical students, the patients themselves were overwhelmingly positive about seeing students. ${ }^{13}$ This was the case even for those who had a very poor performance status.

\section{Study limitations and strengths}

This was a small-scale, regional survey. The FYI doctors' response rate was poor, due in part to the use of university and NHS email addresses to contact them (students didn't use them as often as personal email addresses), and as a result, the views of almost twothirds of FYIs were not captured. Distributing paper copies from the outset might have been more effective in encouraging completion and return of the questionnaires. Similarly, the consultant survey only reflects the views of a small number of FYI supervisors, and as such may not be fully representative.

Questionnaires were completed variably, with many of the free text responses left blank by both the FYIs and consultants. This might have been overcome had interviews been used as the main method for gathering data and discussing personal experiences, though this would have been significantly more time-consuming.

Interviews were only conducted with a small convenience sample of FYI doctors (the first five we asked who agreed). Interviewing a larger number of FYI doctors and in-depth qualitative analysis of their responses may have provided valuable insights into some of the key issues.

We asked about perceptions of 'preparedness', but appreciate that these may not represent actual levels of clinical competence. However, exploring the views of both FYI doctors and consultants provided a more balanced evaluation of behaviour in practice. This study was participatory and constructive. Our findings are informing a review of the palliative care curriculum in Scottish medical schools and could form the basis of a wider, national survey, assisting medical educators in other parts of the UK and internationally.

\section{RECOMMENDATIONS AND CONCLUSIONS}

It is unrealistic to expect that our medical students will graduate feeling adequately prepared to deal with all patients with supportive and palliative care needs. However, undergraduate education should ensure doctors qualify with core competencies that will be developed by subsequent experience and training. Greater awareness of the issues that FYI doctors 
struggle with should inform current dialogue about how we might meet their educational and supportive needs more effectively. We have highlighted that training in managing distressed patients and families, dealing with social issues relating to palliative care and responding to spiritual needs could be improved. Foundation doctors who experience distress should to be able to access support and senior clinicians may need to be more proactive in offering such help.

\section{Undergraduate opportunities}

Curricular pressures are unlikely to allow more designated palliative care teaching time, but clinical teachers in a range of hospital specialties and primary care are well placed to offer students valuable experiences. Providing medical students with more opportunities to be directly involved in the care of people with advanced conditions who are approaching the end of life should go some way to improving foundation doctors' preparedness for practice, and is in line with GMC recommendations. Encouraging medical students to witness patient and family distress, showing them how it is managed, and allowing them to be present when multi-disciplinary team discussions about social, psychological and spiritual care needs as well as medical problems are taking place is a priority. Clinicians should be encouraged to involve medical students as junior team members sharing in the care of people who are dying in all settings. This would be welcomed by many patients provided it is handled sensitively. Practical teaching sessions on prescribing are seen as increasingly important preparation for clinical practice and should include palliative care cases.

\section{Postgraduate opportunities}

Clinical supervisors in all specialties support learning in clinical practice and foundation doctors will have many opportunities to build on their undergraduate training in palliative care. Training for postgraduate supervisors should include ways of addressing the support needs of junior doctors. Foundation doctors need to be able to give and receive support as members of the wider multidisciplinary team. Case-based discussions offer structured opportunities to review and improve competencies in palliative care.

\section{Acknowledgements}

Our thanks go to Ann Aitchison and Harriet Harris who kindly provided administrative support and to Duncan Henderson, who helped us to contact the FYI doctors.

Supplementary appendices are available online at http:// www.rcpe.ac.uk/journal/index.php.

\section{REFERENCES}

I General Medical Council. Tomorrow's doctors [Internet]. London: GMC; 2009 [cited 20I3 Feb 8].Available from: http://www.gmc-uk. org/TomorrowsDoctors

2 Ahmedzai SH, Costa A, Blengini C et al. A new internationa framework for palliative care. Eur J Cancer 2004; 40:2192-200. http://dx.doi.org/I0.1016/j.ejca.2004.06.009

3 Association for Palliative Medicine of Great Britain and Ireland. Consensus syllabus for undergraduate palliative medicine in Great Britain and Ireland [Internet]. Southampton:APM; 2006 [cited 20I3 Feb 8]. Available from: http://www.apmonline.org/documents//297864229] 9199.pdf

4 Paes P, Wee B. A Delphi study to develop the Association for Palliative Medicine consensus syllabus for undergraduate palliative medicine in Great Britain and Ireland. Palliat Med 2008; 22:360-4. http://dx.doi.org//0.I I77/0269216308090769

5 Gibbins J, McCoubrie R, Maher J et al. Recognizing that it is part and parcel of what they do: teaching palliative care to medical students in the UK. Palliat Med 2010; 24:299-305. http://dx.doi. org/I0.II77/02692I6309356029

6 Scottish Government. Living and dying well: a national action plan for palliative and end of life care in Scotland [Internet]. Edinburgh: Scottish Government; 2008 [cited 2013 Feb 8]. Available from: http://www.scotland.gov.uk/Resource/Doc/239823/0066I55.pdf

7 Department of Health. End of life care strategy - promoting high quality care for adults at the end of life [Internet]. London: Department of Health; 2008 [cited 2013 Feb 8]. Available from: http://www.dh.gov.uk/en/Publicationsandstatistics/Publications/ PublicationsPolicyAndGuidance/DH_086277

8 Oliver D. Training and knowledge of palliative care of junior doctors. Palliat Med 1998; 12:297-9. http://dx.doi. org/I0.II91/02692169867502448I

9 Tiernan E, Kearney M, Lynch A et al. Effectiveness of a teaching programme in pain and symptom management for junior house officers. Support Care Cancer 200I; 9:606-10. http://dx.doi. org/10.1007/s005200100269

10 Linklater GT. Educational needs of foundation doctors caring for dying patients.J R Coll Physicians Edinb 20 10; 40: I3-8. http://dx.doi. org/10.4997/JRCPE.2010.104

II Field D, Wee B. Preparation for palliative care: teaching about death, dying and bereavement in UK medical schools 2000200I. Med Educ 2002; 36:56I-7. http://dx.doi.org//0.1046 j.I365-2923.2002.0I232.x

12 Gibbins J, McCoubrie R, Maher J et al. Incorporating palliative care into undergraduate curricula: lessons for curriculum development. Med Educ 2009; 43:776-83. http://dx.doi.org/I0.IIII/ i. I365-2923.2009.03400.x

I3 Arolker M, Barnes J, Gadoud A et al. 'They've got to learn' - a qualitative study exploring the views of patients and staff regarding medical student teaching in a hospice. Palliat Med 2010; 24:419-26. http://dx.doi.org//0.1 I77/0269216310366065 